\title{
HUELGA DE HAMBRE. ESCRITURA Y REPRESENTACIÓN UNA LECTURA DE BOBBY SANDS DESFALLECE EN EL MURO DE CARMen Berenguer
}

\author{
José Salomón Gebhard \\ Universidad Andrés Bello \\ jose.salomon@unab.cl
}

\section{RESUMEN / ABSTRACT}

El artículo plantea una investigación en torno al concepto de migrancia, propuesto por Antonio Cornejo Polar, y su aplicación como enfoque crítico a la representación de la huelga de hambre en el texto poético Bobby Sands desfallece en el muro, de Carmen Berenguer. Se describen las relaciones posibles de este concepto con las definiciones de sujeto subalterno, entendiendo a este último como una forma de conceptualización híbrida y plural. El análisis del texto de Berenguer considera la figura de la huelga de hambre como la alternativa de una representación subalterna, sostenida en el uso del cuerpo como material de escritura, mostrando el rechazo a los códigos literarios y hegemónicos de representación simbólica. La huelga de hambre constituye una expresión que convoca sus propios criterios de interpretación y supone una migrancia que se desplaza desde el discurso, letrado y literal, hacia una marca signada por la representación del cuerpo.

Palabras clave: representación, huelga de hambre, migrancia, sujeto subalterno, cuerpo.

This article presents a research about the concept of migrancy proposed by Antonio Cornejo Polar, and its application as critical approach to the representation of the hunger strike in the poetic text of Carmen Berenguer; Bobby Sands desfallece en el muro. The possible relations of this concept are described with the definitions of subaltern subject. Understanding the last one as a form of hybrid and plural conceptualization. The analysis of the poetic text of Berenguer considers the hunger strike as an alternative of a subaltern representation, sustained in the use of the body as writing material, also raising the rejection to literary and hegemonic codes of symbolic representation. In this sense, the hunger strike is an expression that calls for its own interpretation criteria and it supposes a migrancy that moves from the speech, literate and literal, to a stamp characterized by the representation of the body.

KEYWORDS: representation, hunger strike, migrancy, subaltern subject, body. 
Las gentes se iban acostumbrando a la rara manía de pretender llamar la atención como ayunador en los tiempos actuales y, adquirido este hábito, quedó ya pronunciada la sentencia de muerte del ayunador. Podía ayunar cuanto quisiera, y así lo hacía. Pero nada podía ya salvarle; la gente pasaba por su lado sin verle. ¿Y si intentara explicarle a alguien el arte del ayuno? A quien no lo siente, no es posible hacérselo comprender.

El artista del hambre. Kafka

\section{LA HUELGA POÉTICA DE CARMEN BERENGUER}

La producción textual de Carmen Berenguer comienza con la publicación en 1983 de Bobby Sands desfallece en el muro, momento histórico que marca la emergencia tanto de movimientos contestatarios a la dictadura de Pinochet como de voces disidentes en las representaciones literarias de la época. No obstante, es improcedente inscribir este texto con propiedad dentro de una tendencia testimonial, pues ejecuta una evidente ruptura frente a los códigos literales de referencialidad extratextual del testimonio. En cambio, se postula aquí que Berenguer, ya desde este texto inaugural, establece una distancia del campo literario y de sus caracterizaciones más evidentes en el contexto cultural de la época, como la politización de la función representacional de la literatura, para ejercer de modo contrario una suerte de condición migrante en su producción literaria. En general, toda la obra escrita por Carmen Berenguer recrea espacios y personajes disidentes del campo cultural chileno, que desde su excentricidad reinterpretan las voces urbanas y marginales de la sociedad: "Carmen Berenguer trabaja con los bordes, en personajes, en situaciones, y no sólo al enfocar segmentos de ciudades chilenas o a representantes de nuestros pueblos originarios sino, asimismo, al realzar la experiencia de un extranjero, que da título a su primer libro" (Bianchi 179-180).

En una primera etapa de su producción, Berenguer se destaca por la elaboración de un discurso poético que, sin asumir la retórica testimonial de la expresión literal de la realidad, configura espacios y personajes que trascienden la funcionalidad política del momento, para establecer un espacio de ruptura frente a los lenguajes hegemónicos tanto de la política como de la literatura, como ocurre en los textos publicados bajo dictadura Bobby Sands desfallece en el muro (1983) y Huellas de siglo (1986). Esta misma poética disidente encontrará su continuidad en el período de postdictadura, 
especialmente en Naciste pintada (1999) y mama Marx (2006), textos que recogen las voces de sujetos delincuentes y vagabundos, respectivamente. Su último texto, Mi Lai (2015), refuerza esta trayectoria al instalar en el recuerdo, en la marginalidad del pasado, el relato poético de un viaje que, junto con ser autobiográfico, describe críticamente elementos propios de la cultura de masas de la década de los sesenta.

En este contexto de producción, Bobby Sands desfallece en el muro asume la expresión de la voz del huelguista de hambre irlandés Bobby Sands, muerto por inanición voluntaria en 1981 en la cárcel de Maze, en protesta por las condiciones de encarcelamiento a que estaban sometidos los presos políticos - de hecho, no se les reconocía la calidad de tales- del Ejército Republicano Irlandés (IRA). En resumen, el texto describe la evolución de la huelga de hambre y sus consecuencias corporales. Para explicar las razones por las que Berenguer recurre a la figura extranjera de Bobby Sands, en el contexto de la lucha antidictatorial en Chile, en este artículo se considera que la condición migrante antes mencionada opera mediante un ejercicio representacional que instala un sujeto y un discurso subalternos de conformación híbrida, en cuanto a las múltiples perspectivas que comparecen en su definición: "La subalternidad es una identidad relacional más que ontológica, es decir, se trata de una identidad (o identidades) contingente y sobredeterminada" (Beverley 59). La hibridación representacional así considerada implica un conjunto de características disgregadas, a partir de cada cual opera una posible definición contingente de la subjetividad migrante y que posibilitarían su categorización como sujeto subalterno, "aquel cuya identidad es su diferencia" (Spivak, Puede hablar 46) ${ }^{1}$. Esta pluralidad de características permite suscribir el concepto de "migrancia" para llevar a cabo el análisis del texto poético de Berenguer, en tanto se propondrá que la representación del subalterno se exhibe bajo los signos transitivos y descentrados de una retórica de la migración, término acuñado por Antonio Cornejo Polar, para quien

\footnotetext{
Para Spivak, la identidad subalterna supondría un efecto de sujeto: "aquello que parece obrar como sujeto puede ser parte de una inmensa red discontinua (texto en sentido general) de hebras, que pueden llamarse política, ideología, economía, historia, sexualidad, lenguaje, etc." ("Estudios" 44); y más adelante: "habría que leerlo (al efecto de sujeto subalterno), entonces, como un uso estratégico del esencialismo positivista en aras de un interés político escrupulosamente visible" ("Estudios" 45). La discontinuidad entre estas hebras, o efectos de sujeto, aporta la posibilidad de incorporar la variabilidad de perspectivas y, por lo tanto, la capacidad de migrancias identitarias del subalterno.
} 
El discurso migrante es radicalmente descentrado, en cuanto se construye alrededor de ejes varios y asimétricos, de alguna manera incompatibles y contradictorios de un modo no dialéctico. Acoge no menos de dos experiencias de vida que la migración, contra lo que se supone en el uso de la categoría de mestizaje, y en cierto sentido en el del concepto de transculturación, no intenta sintetizar en un espacio de resolución armónica; imagino -al contrario-que el allá y el aquí, que son también el ayer y el hoy, refuerzan su aptitud enunciativa y pueden tramar narrativas bifrontes y -hasta si se quiere, exagerando las cosas- esquizofrénicas. Contra ciertas tendencias que quieren ver en la migración la celebración casi apoteósica de la desterritorialización (García Canclini), considero que el desplazamiento migratorio duplica (o más) el territorio del sujeto y le ofrece o lo condena a hablar desde más de un lugar. Es un discurso doble o múltiplemente situado (6-7).

Aunque Cornejo Polar se refiere específicamente a la migración ocurrida en el ámbito andino peruano y sus representaciones literarias, sobre todo en Arguedas, no niega la posibilidad de aplicar esta categoría de modo más amplio, sosteniendo que "a partir de tal sujeto [migrante], y de sus discursos y modos de representación, se podría producir una categoría que permita leer amplios e importantes segmentos de la literatura latinoamericana -entendida en el más amplio de sus sentidos- especialmente los que están definidos por su radical heterogeneidad" (3). En definitiva, la categoría de migrancia que se utilizará en el análisis textual siguiente supone un sujeto subalternizado por diversos contextos hegemónicos definidos en términos de clase, género o lengua. En este sentido, la representación del huelguista irlandés en el contexto chileno implica un movimiento de migrancia simbólica que pluraliza las lecturas del texto de Berenguer, traspasando los límites de lo meramente testimonial.

De este modo, la adopción de la figura del huelguista irlandés en el texto de Berenguer atrae conceptos como la habitabilidad de mundos subalternos múltiples, que consiste en "la capacidad de habitar una pluralidad de mundos como una característica constante de los discursos subalternos desde la Conquista hasta nuestros días" (Rabasa 108); y cosmopolitismo subalterno, definido como "la forma cultural y política de la globalización contrahegemónica. Este es el nombre de los proyectos emancipatorios cuyas demandas y criterios de inclusión social van más allá de los horizontes del capitalismo global" 
(De Sousa Santos 29) ${ }^{2}$. El carácter cosmopolita del proyecto escritural de Berenguer radica, efectivamente, en la incorporación de un referente político a gran distancia -geográfica y cultural- del contexto chileno, pero también reitera el alejamiento de los patrones formales del género testimonial, del criterio de "lo visto y vivido" y del carácter "verídico" de esta construcción discursiva. Esta opción de escritura representa tanto una migrancia política como una migrancia discursiva, en tanto la primera marca un distanciamiento respecto de las definiciones de lo nacional, mientras en la segunda dicho distanciamiento opera a partir del sistema literario oficial pero que, por más que se encuentre sometido a la propuesta contraoficial del género testimonial, de todos modos permanece en los márgenes conceptuales y hermenéuticos de lo nacional literario. Por ello, el libro de Berenguer es, por una parte, un libro testimonial pero en un nivel de lectura donde lo testimonial no rige: en la alusión indirecta, en la pluralidad interpretativa y en la oblicuidad del sentido (¿cómo referirse a la situación chilena a partir del contexto irlandés? ${ }^{3}$ ). Por otra parte, trasciende lo testimonial al romper la condición primordial de este género: la presencia de un referente extratextual históricamente discernible, imponiendo, en cambio, las pautas de la ficción sobre un nombre, un cuerpo y una escritura, para fabular en conjunto la representación de la huelga de hambre.

Se puede sostener, entonces, que el texto de Berenguer, y su circulación artesanal, implican en términos generales una distancia de la escritura y del formato objetual del libro ${ }^{4}$. Este artículo propone que su primer libro inaugura en su trayectoria un movimiento distanciador de la escritura y de sus principales condicionantes: linealidad, sucesividad y jerarquía de los signos. En Bobby Sands, el alejamiento de la escritura produce la ruptura de las tres condicionantes referidas mediante operaciones semióticas que

2 El autor utiliza este término para referirse, dentro de los efectos de la globalización neoliberal, a la posibilidad de un cosmopolitismo político-jurídico que sobrepase las particularidades de nacionalidad y fronteras estatales.

Una alusión indirecta al estribillo del himno nacional chileno, como huella testimonial, se puede rastrear quizás en los siguientes versos de Bobby Sands: "Puro mar es tu aroma / en mi cuarto / son tus fauces diente / es tu espuma la roca / que tapiza tu cielo feraz" (24).

La primera edición de este texto apareció impresa en forma artesanal en 1983 con una tirada de apenas doscientos ejemplares. La edición que aquí se utiliza corresponde a "Bobby Sands desfallece en el muro". Carmen Berenguer. La gran hablada. Santiago: Editorial Cuarto Propio. 2002. pp. 7-36. 
se les contraponen: espacialidad de la letra, ruptura sintáctica e hibridación semántica. Al respecto, es importante señalar que varios de los poemas recrean formas verticales e inclinadas, como si estuvieran escritos en las paredes de la celda, haciendo de esta el soporte de la escritura ${ }^{5}$; incluso, el acto de desfallecer en el muro, como lo indica el título, suscita la emergencia de un habla alternativa, incoherente y subalterna respecto de cualquier código representacional hegemónico, susurros y quejidos en el desfallecimiento de la voz y del cuerpo. Además, el texto se enmarca por dos formas rígidamente codificadas de escritura: comienza con un epitafio, como lápida que anuncia la muerte, y concluye con una pregunta: "Alguien podría escribir un poema / de las tribulaciones del hambre. / Yo podría, pero ¿cómo terminarlo?” (36). Estos marcos formales son, en definitiva, las figuras retóricas que constriñen y encierran toda la enunciación de este texto, haciendo de su discursividad una verdadera "cárcel del lenguaje" y de la cual se pretende escapar mediante la migrancia simbolizada en la huelga de hambre.

De igual modo, los poemas se organizan temporalmente mediante fechas, por una sucesión cronológica que marca el tiempo fatal y anuncia el desenlace de la huelga, ellas son el andamiaje y los barrotes simbólicos por donde corre la negación de la escritura, por donde evoluciona el deseo de negar la canonicidad de la escritura hegemónica, aquella que no solo encierra y constriñe signos y símbolos de la cultura dominante, sino también al propio cuerpo en huelga. En otras palabras, el libro mismo asume la forma de una cárcel. En un sentido similar a este distanciamiento y negación, o migrancia, de la escritura aquí propuesto, Julio Ortega afirma que la autora "empieza borrando al lenguaje en el mismo momento en que lo enuncia. Carmen Berenguer escribe desescribiendo. Su escritura es un arrebato, un robo del fuego civil" (36).

Asimismo, la inscripción de la escritura en las paredes de la celda atrae otro rasgo evidente en este texto, la presencia de la oralidad. Si bien esta se expresa mediante una linealidad temporal, el muro permite una instantánea

Como antecedente, se debe recordar que, durante su encarcelamiento, los presos políticos del IRA decidieron como forma de protesta negarse al aseo corporal diario y, además, embadurnaron sus celdas con excrementos. En esta particular forma de protestar coexisten dos hechos fundamentales: por un lado, el recurso al excremento como registro corporal de escritura anuncia la antesala de la huelga de hambre y de la utilización del cuerpo como soporte escritural y, por otro lado, el trazo del excremento postula una analogía con la escritura oficial y hegemónica, considerada peyorativamente como una mierda. 
visual que rompe la lógica de la sucesión literal, produciendo un efecto de repetición como característica central en la representación de la oralidad ${ }^{6}$ como habla subalterna; así se evidencia en la mayoría de los poemas que dibujan la página como si fueran las paredes de la celda, reiterando incesantemente la opción por el balbuceo del cuerpo en huelga, como lo reconoce Eugenia Brito: "El texto es un himno, pero también un graffiti: conjuga así sobre la página la oralidad y la escritura. Los grafos escritos supuestamente por Bobby Sands en su celda son la expresión de una libertad creativa elegida por sobre todas las otras" (167). La repetición es una constante en la oralidad, una ruptura de la jerarquía semiótica, que manifiesta la urgencia por comprobar el canal comunicativo y rechazar la continuidad formal de la escritura sobre "papel", es la elección por una libertad creativa, como lo sugiere la cita anterior. Sin embargo, es más importante aún agregar que en la representación de esta oralidad se asumen formas corporales de expresión más allá de todo sistema lingüístico: el balbuceo, el susurro, el quejido, la náusea y el vómito son signos que implican una corporalización del habla: "Vacío en la lengua seca / habla, porque es lo único / digna lengua" (14); "Saliva la entrada en la garganta / que traga a bocanadas / disuelta en la lengua la sal" (15); "Náuseas la náusea / con los labios pintados / vomita la muerte" (26). Todas estas formas expresivas materializan en el cuerpo representando la viabilidad de un habla contrahegemónica, manifiestan una migrancia desde la escritura oficial y la condena a hablar desde más de un lugar, como afirma Cornejo Polar. La migrancia entre estos espacios lingüísticos diversos, habitarlos sin perder su radical especificidad, torna al cuerpo subalterno un objeto de su propia tarea de traducción, en la medida en que las formas señaladas, susurro, vómito, náusea, son los signos incodificables que hacen del cuerpo en huelga una escritura del cuerpo.

La posibilidad de migrancia entre mundos lingüísticamente diversos debe entenderse no solo como la coexistencia de lenguas oficiales gramaticalmente sistematizadas, sino también como la posibilidad de incorporar y migrar entre mundos de representación discursiva diversa, de códigos ajenos a la escritura, como la propia oralidad e, incluso, de formas simbólicas que, en

6 En la representación de la oralidad, en el problema de su conceptualización, creemos encontrar cierta similitud con lo que Walter Ong, aunque en otros contextos, denomina oralidad secundaria, como una oralidad posterior a la escritura y signada conflictivamente por ella. Ong jocosamente afirma que pensar en la "literatura oral es algo parecido a pensar en los caballos como automóviles sin ruedas" (21). 
su precariedad, expresarían un habla subalterna, como el susurro, el quejido y el desfallecimiento, cuestionando así la subordinación de una lengua hegemónica por otra $y$, en consecuencia, la subordinación de un sistema cultural por otro: "La noción de mundos múltiples no contradictorios nos permite pensar en sujetos que a la vez sean mestizos, híbridos y nómadas, sin incurrir en la celebración de una síntesis cultural, o limitarse a ver un conflicto entre dos o más culturas. Las diferencias cognitivas en las lenguas dan lugar a las nociones de mundos relativamente inconmensurables con espacios discursivos propios" (Rabasa 112). Por eso, también Rabasa otorga importancia al hecho de la traducción y la migrancia discursiva como un habitar distintos espacios lingüísticos, para él la traducción no puede ser solo la relación binaria entre dominante y dominado, ni tampoco una romántica relación de igualdad horizontal; por el contrario, reconoce que el subalterno tiene una capacidad de habitar el mundo lingüístico del otro sin perder su radical especificidad: “¿Por qué definirse en oposición al lenguaje de los que ejercen el poder cuando uno puede habitar, es decir, actuar en y sobre sus mundos, sin abandonar los propios?" (116). Con ello, Rabasa propone la traducción como una posibilidad de migrancia entre distintos sistemas simbólicos de representación.

Paradojalmente, la corporalización del habla, del susurro, del quejido y del desfallecimiento, abre la posibilidad del silencio, pues hay una voz que se calla porque el cuerpo se manifiesta y cuyo silenciamiento llega a su culminación en la pregunta final que queda en suspenso. El texto de Berenguer es un libro que camina en dirección al silencio, como el cuerpo en huelga avanza adelgazándose hacia su desaparición definitiva. El silencio y el anuncio de la muerte se vuelven recursos discursivos para expresar el rechazo a los códigos dominantes de representación lingüística: "Me entrego a una agonía lenta / como único modo de cambiar / la pólvora por jardines de paz" (29). Por último, el espacio carcelario, que la poeta denomina "libre mar de mi celda" (35), en su asimilación como espacio de escritura recoge una figura constante en la tradición literaria que, pese a su carácter canónico, recrea la imposibilidad representacional de aquello que no solo ha sido escrito en el "libre mar de mi celda", sino también en el agua y en el viento -por lo general las promesas-como soportes imposibles de perpetuar los signos escritos.

No obstante, el mayor gesto de silencio es aquel que realiza Berenguer al ocultar su propia voz enunciante de sujeto femenino, pues emigra de sí misma para recrearse en la voz y el cuerpo de Bobby Sands. Esta migrancia 
busca, por una parte, solidarizar con el cuerpo sin determinación genérica del preso político, sea en Chile o en Irlanda, una suerte de cuerpo subalterno cosmopolita que intensifica en su transmigrancia el repudio ante definiciones tanto geográficas como de género; por otra parte, busca eludir aquello que más condicionó la contingencia corporal en la dictadura chilena: la tortura como mecanismo de patentización del cuerpo. Y no solo la tortura entendida como mecanismo de represión y representación política, sino también como forma de encasillar, representar y encarcelar al sujeto femenino productor de escritura. Así, la escritura de Berenguer expresa una estrategia de resistencia frente al sistema literario chileno que constriñe la representación del sujeto femenino, como señala Brito: "es la entrada en la poesía chilena de un tipo diferente de concebir la literatura, no como una actividad emotiva, que era la dominante entre las mujeres: el llanto nostálgico por el amor perdido o bien la dulzura o el desencanto de la relación con las cosas: preferentemente con la naturaleza o con las labores propias del quehacer doméstico" (167). Similar fuga de las restricciones del sistema literario, de sus opresiones conceptuales, se evidencia en el hecho de que la poesía de Berenguer también rehúsa incorporar todo lirismo emotivo y romántico, el juego de las imágenes y comparaciones metafóricas, acudiendo más bien a una estructuración metonímica de la escritura. Metonimia antes que metáfora, en el sentido que la primera permite una mayor libertad en la contigüidad y asociatividad de ideas, pertinentes a un discurso descentrado que "repite el azaroso itinerario del migrante" (Cornejo 10). No existe centro que estructure el espacio textual ni el espacio carcelario, sino un devenir permanente (¿qué devenir no tiene tal cualidad?) en el "ir y venir de la metonimia" (Cornejo 10), en la habitabilidad de mundos y atributos diversos, en la organizada dispersión que define la representación de escritura y cuerpo subalternos.

Todas las migrancias señaladas conducen, en definitiva, a instalar una escritura del cuerpo -"haz una raya en mi ombligo / haz una raya en la pared" (33)- que tiene como eje representacional la figura de la huelga de hambre. Esta es una figura que de suyo elude toda estabilidad semiótica y toda codificación restrictiva, para, en cambio, resaltar la precariedad de un imaginario corporal en perpetuo trance a su desaparición, a su adelgazamiento, a su silencio y a su obliteración que es, en su centro etimológico, un dejar de lado la letra. 


\section{CONCLUSIONES}

La representación de la huelga de hambre permanece en el umbral de la escritura, tanto la deniega como código simbólico hegemónico, como a la vez también la asume como posibilidad de visibilización y resistencia política. El análisis anterior se ha centrado fundamentalmente en dicha migrancia y en la forma que adoptan los recursos discursivos en el texto de Berenguer: susurros, balbuceos, quejidos, como modo de instalar un habla frente a la censura dictatorial y ante cuya prohibición Bobby Sands legitima su propia enunciación: "habla, porque es lo único/digna lengua" (14), ya sea con un balbuceo desfalleciente o con el anuncio de una posibilidad poética que supere la censura, "como única forma de esperar la alondra/y nuevas primaveras" (29). En cambio, ahora las conclusiones pretenden reflexionar sobre el segundo polo, la eventualidad de visibilizar una práctica corporal. Es así que el huelguista requiere siempre de espectadores que confirmen su hazaña, su cuerpo como trazo escritural necesita lectores que descifren las marcas que va dejando la temporalidad del hambre. El huelguista hace de su cuerpo un actor sobre el escenario de la cárcel y de la letra, él mismo se da a leer como objeto de sus propios parlamentos. En la teatralidad de la huelga de hambre el cuerpo se anuncia como espectáculo. El cuento El artista del hambre de Kafka recoge este motivo, el ayuno como arte; en esta narración, el ayunador dentro de su jaula de circo se transforma en la exhibición de sí mismo, es espectador de su hambre como también recrea al hambre como espectáculo. Incluso, el circo en la narración de Kafka y la cárcel en el poemario de Berenguer son escenarios análogos sobre cuyo tablado se dramatizan corporalidades que fundan un ejercicio representacional en la materialidad del cuerpo, ajeno a todo proceso de conceptualización. Por eso, el cuerpo es siempre un subalterno irrepresentable, deportado de toda consideración simbólica: es espectáculo puro.

Ante la exhibición de esta materialidad irrefutable -aunque inasible-, la única manera de comprobar los efectos corporales de la huelga de hambre es recurrir al disciplinamiento médico del cuerpo, a su biologización, se describen los síntomas y se sistematizan las consecuencias del ayuno, se examina el cuerpo como proceso clínico, se le ausculta y se pronostica lo que la lógica científica dictaminará como anuncio verdadero: diagnóstico de inanición voluntaria. A través del contacto la vigilancia médica ejerce sus estrategias de disciplinamiento. Mientras en el texto de Berenguer la 
simulación de escritura en las paredes materializa al cuerpo, y hace de la cárcel un cuerpo (trastocando la tradición mística que veía al cuerpo como una cárcel), en el cuento de Kafka el ayunador debe sacar un dedo por entre los barrotes de la jaula, de modo que los otros lo palpen y así certifiquen el éxito de su ayuno, pues los otros siempre corroboran la verdad del espectáculo del ayuno mediante el sentido del tacto, como si la vista no bastara; solo al tocar el cuerpo en huelga se vuelve realidad su desaparición paulatina. Es también lo que hacía la bruja del cuento infantil de Hansel y Gretel; engañada por los niños, que le ofrecían a la bruja cegatona un hueso de pollo por entre los barrotes de su jaula, ella creía palpar los dedos infantiles y, así, comprobar los resultados del ayuno simulado. El espectador del ayuno duda de la voluntad y de la veracidad de tal acto, cumpliendo el rol de la bruja malvada, como si pidiera tocar los dedos del huelguista para comprobar que efectivamente ha adelgazado.

En la materialidad del acto de ayuno, entonces, la huelga de hambre instala la representación corporal como extrañamiento del código simbólico dominante de la letra: en definitiva la escritura de la huelga es también la huelga de la escritura. Se recurre a la huelga cuando ya otras huelgas no han dado resultados dentro del acuerdo social vigente. La huelga de hambre es un quiebre y suspensión de otras huelgas, en ella predomina el sentido absoluto de interrupción del pacto social, pues se rompe el ejercicio básico de socialización que supone el acto de comer. El huelguista detiene la actividad económica primordial de satisfacción de la primera necesidad y se separa, emigra, de todo lazo social. Con ello, pierde el sentido de lo colectivo y toda su lucha política se vuelve espectacularización de su intimidad, de modo similar a la conciencia anoréxica que ha perdido la exacta noción de sí misma, ya no ve su propio reflejo escuálido sino, en cambio, toda su funcionalidad corporal consiste en exhibir la imagen de sí pero de la cual nada se le devuelve. Ni el huelguista ni el anoréxico logran verse a sí mismos, salvo quizás como víctimas propiciatorias, de ahí que deseen -y a menudo lo logren- que toda la comunidad viva en función de su proceso de ayuno, centrada en ellos, y a la cual le endosan la deuda que les otorga su sacrificio y, como tal, Bobby Sands exhibe su proceso: "Entrego mi vida como una acción de amor" (29), con lo cual el huelguista convierte a la comunidad en su deudora moral gracias al crédito de su propio cuerpo. En esta perspectiva, el huelguista se sacrifica como sujeto pero reinstalando un cuerpo, resaltando la diferencia entre uno y otro: sujeto como construcción política y cuerpo como abyección pura, un cuerpo abyecto que es el repudio fundacional del 
sujeto 7 . Cuerpo y sujeto en los umbrales de la irrepresentabilidad. Por eso, la representación de la huelga es, asimismo, la huelga de la representación.

\section{BIBLIOGRAFÍA}

Berenguer, Carmen. "Bobby Sands desfallece en el muro". La gran hablada. Santiago: Editorial Cuarto Propio, 2002. 7-36.

Beverley, John. Subalternidad y representación. Madrid: Iberoamericana, 2004.

Bianchi, Soledad. "Escrituras de mujeres / Chile / Siglo XX". Lecturas críticas. Lecturas posibles. Concepción: Ediciones Universidad del Bío-Bío, 2013. 172-183.

Brito, Eugenia. "La oralidad como proceso de producción de la escritura". Campos minados. Literatura post-Golpe en Chile. Santiago: Cuarto Propio, 1994. 165-172.

Cornejo Polar, Antonio. "Una heterogeneidad no dialéctica: sujeto y discurso migrantes en el Perú moderno". Revista Iberoamericana Vol. LXII, no 176-177. Julio-diciembre, 1996. Consultado en ene. 2015 de http://www.cholonautas.edu.pe/modulo/upload/corn.pdf. 1-12.

De Sousa Santos, Boaventura. Para descolonizar Occidente. Más allá del pensamiento abismal. Buenos Aires: Consejo Latinoamericano de Ciencias Sociales CLACSO; Prometeo Libros, 2010.

Kristeva, Julia. Poderes de la perversión. México: Siglo XXI Editores, 2010.

Ong, Walter. Oralidad y escritura. Tecnologías de la palabra. Bogotá: Fondo de Cultura Económica, 1999.

Ortega, Julio. "Carmen Berenguer". Caja de herramientas. Prácticas culturales para el nuevo siglo chileno. Santiago: Lom Ediciones, 2000. 29-36.

Rabasa, José. "Límites históricos y epistemológicos en los estudios subalternos". Ed. Mabel Moraña. Nuevas perspectivas desde/sobre América Latina: el desafio de los estudios culturales. Santiago: Editorial Cuarto Propio/Instituto Internacional de Literatura Iberoamericana, 2000. 107-118.

Spivak, Gayatri Chakravorty. ¿Puede hablar el subalterno? Buenos Aires: El cuenco de plata, 2011.

"Estudios de la subalternidad. Deconstruyendo la historiografía". Sandro Mezzadra et al. Estudios postcoloniales. Ensayos fundamentales. Madrid: Traficantes de Sueños, 2008. 33-67.

\footnotetext{
"Si es cierto que lo abyecto solicita y pulveriza simultáneamente al sujeto, se comprenderá que su máxima manifestación se produce cuando, cansado de sus vanas tentativas de reconocerse fuera de sí, el sujeto encuentra lo imposible en sí mismo: cuando encuentra que lo imposible es su ser mismo, al descubrir que él no es otro que siendo abyecto. La abyección de sí sería la forma culminante de esta experiencia del sujeto a quien ha sido develado que todos sus objetos sólo se basan sobre la pérdida inaugural fundante de su propio ser" (Kristeva 12). Cursivas en el original.
} 